\section{Animals in Medical Research}

Few topics give rise to such misunderstanding, misrepresentation, and even emotion as the subject of using animals in medical research. It is pertinent, therefore, to consider where scientific developments are leading us in this respect.

In the interests of increasing the speed, accuracy, and sensitivity of assays some modern techniques are doing much to replace animals. Many of the vitamins, which in the beginning were assayed in biological tests, are now so easily synthesized that chemical analysis has replaced the biological assay. Tissue-culture techniques have made great advances in virology. No more than two decades ago infection of susceptible animals was the only means of differentiating one virus from another. Today we learn much from the characteristic cytopathic degeneration caused by viruses in cell cultures, and the neutralization of such activity by specific antiserum characterizes the virus, thus eliminating the use of animals. Indeed there are several viruses that can be detected only in specific cell cultures, and perhaps the most striking example of this is a virus endemic to one species of monkey which can be detected only in the cell cultures of another species of monkey. The most recent developments in the hybridization of viruses have been studied in cell cultures with little use of animals.

Cultures of human cells that can be grown in vitro are well established in public-health work because of their unique sensitivity to some viruses of the upper respiratory tract. The cells are free from contaminating viruses and maintain a normal nuclear structure throughout their life. Thus their suitability is being investigated for the production of virus vaccines, to eliminate the use of animals. Already over 170,000 children in Yugoslavia have been given oral poliomyelitis virus vaccine prepared in these cells, and some 5,000 American Servicemen have been given adenovirus type 4 vaccine similarly prepared.

Diphtheria toxin and antitoxin can be assayed in cell cultures or by haemagglutination techniques, and the concentration of a number of antigens can be measured by geldiffusion, again avoiding the use of animals. Similar trends towards in vitro techniques are evident in fields other than microbiology. For example, in pregnancy tests the use of immature female mice was replaced by South African frogs, and they in turn have given way to the gonadotrophin-coated latex particle.

But despite the development of such a variety of in vitro techniques, it would be a mistake to expect that the overall use of animals will be greatly reduced. Research into the development of a prophylactic for every major disease has been materially advanced by the use of laboratory animals. Even though all these modern techniques were available, the measles virus, isolated and attenuated by Enders and his colleagues, was considered safe for clinical trial in children only when it had failed to infect monkeys. There was no other way of assessing this safety. Again, though American workers have successfully attenuated rubella virus in cell cultures, the decision to test the virus in children was taken only after it was shown that vaccinated monkeys did not excrete the virus and transmit the disease to cage mates.

In biological research outside the field of microbiology there would appear to be many instances when the use of laboratory animals remains imperative. Anaesthetics could not be tested in man without first being exhaustively tested in animals, and many surgical techniques today-for instance, organ grafting-would not be possible without experiments on them. The disastrous effects of thalidomide on the foetus might have been avoided had it been known that inoculation of pregnant rabbits would have shown the teratogenicity of the drug. In fact it is doubtful whether any new drug will now be used in man until adequate data on toxicity and teratogenicity have been obtained from tests on animals. For many reasons research scientists often wish to adopt only in vitro techniques, but the fact remains that most drugs and many operations are made safer for man by prior testing on animals.

\section{New Hypotensive Drug}

Clinical experience with a new hypotensive drug, debrisoquine, is reported this week in the B.M.F. by Drs. A. H. Kitchin and R. W. D. Turner from Edinburgh (page 728) and by Professor W. I. Cranston and his colleagues from Oxford (page 732). The list of hypotensive drugs ever lengthens. What is the need to add a further drug with a straight peripheral sympathetic-blocking action to the ones we already have? Does debrișoquine offer any advantages over others ?

Like guanethidine, bretylium, bethanidine, and methyldopa, debrisoquine selectively blocks the peripheral sympathetic nervous system without antagonizing the effects of endogenously released or injected adrenaline and noradrenaline and without affecting the parasympathetic system. Like these drugs, debrisoquine produces a postural hypotension, which is further exaggerated on exercise. With reduction of blood-pressure goes a liability to dizziness on exercise or sudden movement, and this side-effect, like its others, is a direct result of the pharmacological action.

Compared with guanethidine, debrisoquine seems equally effective in lowering blood-pressure, but like bethanidine it has the advantage of a much shorter duration of action. Tolerance develops, but not so seriously as with bretylium, and control can usually be regained by giving the patient thiazides. The Edinburgh workers found side-effects to be less frequent than with either methyldopa or guanethidine, but this unexpected advantage has yet to be observed in Oxford. Diarrhoea was the most frequent side-effect, and others included tiredness and muscle weakness, nasal stuffiness, and failure of ejaculation, as with the other drugs in this group.

Methyldopa bridged the gap between the useful and less potent combination of thiazides plus low-dosage reserpine and the more potent but less easily regulated guanethidine. While the sympathetic blocking drugs (and this presumably includes debrisoquine) lower blood-pressure by lowering cardiac output, methyldopa also reduces the raised systemic vascular resistance and has more effect on the blood-pressure in recumbency than the other drugs. ${ }^{12}$ This should make methyldopa the preferred choice, but unfortunately it is not always effective in severe hypertension. Moreover, methyldopa frequently causes somnolence and less often pyrexia and even anaemia and jaundice.

1 Kirkendall, W. M., and Wilson, W. R., Amer. 7. Cardiol., 1962, 9, 107. 2 Dollery, C. T., Harington, M., and Hodge, J. F., Brit. Heart $\mathcal{f}$., 1963, 25,670

s Luke, R. G., and Kennedy, A. C. Brit. med. 7., 1964, 1, 27.
4 Hans, S. F., and Kopelman, H., ibid., 1964, 1, 736.

5 Johnston, A. W., Prichard, B. N. C., and Rosenheim, M. L., Lancet, 1964, 2, 659. 